\title{
Tempered Bainite and Martensite Embrittlement in Microalloyed Steel for Forged Railroad Wheel to Heavy Haul Application
}

\author{
Domingos José Minicucci * (D), Renato Lyra Villas Boas ${ }^{b}$, Márcio Quintino $^{b}$, \\ Solange Tamara Fonseca ${ }^{a}$ (D), Andrei Bavaresco Resende ${ }^{a}{\text { Paulo Roberto } \text { Mei }^{a}}^{(D)}$ \\ ${ }^{a}$ Universidade Estadual de Campinas, Faculdade de Engenharia Mecânica, Departamento de \\ Engenharia de Manufatura e Materiais, R. Mendeleyev, 200, Cidade Universitária, 13083-860, \\ Campinas, SP, Brasil \\ ${ }^{b}$ MWL Brasil Rodas \& Eixos Ltda., Rod. Vito Ardito, s/n, Jardim Campo Grande, 12282-535, Caçapava, \\ SP, Brasil
}

Received: September 18, 2020; Revised: January 20, 2021; Accepted: February 24, 2021

\begin{abstract}
This research shows two new microalloyed steels with niobium $(\mathrm{Nb})$ for railroad wheels $(\mathrm{Nb} 1$ and $\mathrm{Nb} 2$ ) applied on heavy haul transportation (load over 30 tons/axle). The steels have mixed microstructure composed of pearlite and bainite (finished wheel rim section), and another one composed of martensite with bainite (black wheel section removed on machining) obtained by continuous cooling quenching heat treatment followed by tempering. The bainitic and martensitic microstructure are sensitive to the temper embrittlement phenomenon; therefore, knowing the embrittlement temperature range of these steels is mandatory in order to avoid such an event in the tempering process. Charpy specimens were extracted from the rim of railroad wheels, austenitized $\left(860^{\circ} \mathrm{C}\right)$, quenched in water for four minutes, and tempered at different temperatures to obtain the embrittlement curve. Three materials were compared: AAR (Association of American Railroads) Class C steel with pearlitic microstructure (not sensitive to embrittlement), $\mathrm{Nb} 1$, and $\mathrm{Nb} 2$ microalloyed steels with martensitic, bainitic, and pearlitic microstructures. The microalloyed steels have niobium $(\mathrm{Nb})$, molybdenum (Mo), and silicon ( $\mathrm{Si}$ ) addition. The effect of Si content and the microstructure (analyzed by Scanning Electronic Microscope (SEM)), regarding the embrittlement phenomenon, was also studied. The microstructure of Nb2 steel was analyzed by with Transmission Electronic Microscope (TEM) for improving its characterization.
\end{abstract}

Keywords: microalloy steel, temper embrittlement, bainite, railroad wheels.

\section{Introduction}

There has been a significant development in steel for railroad wheels over the last 10 years, especially with the introduction of microalloyed steel wheels, called class D wheels, by the AAR (Association of American Railroads) in 2011. The axle load on heavy haul railways (load over 30 tons/axle) has been increasing yearly. The pearlitic microstructure (standard for railroad wheels) provides its resistance limit. For this reason, other options in terms of wheel microstructure, such as bainite, have become necessary ${ }^{1 ; 2}$. Currently, the axle load in some railroads in Australia is over 40 tons/axle, while in Brazil it has achieved 35 tons/axle ${ }^{3}$. Bainite has higher mechanical resistance associated with higher toughness than those of pearlite, which are two important characteristics for wheel material ${ }^{4}$. Wear tests show that microstructures consist of ductile and brittle phases; therefore, structures with more than one phase, such as pearlitic and bainitic, are more efficient in abrasion resistance than the monophasic ones, like martensitic ${ }^{5}$. In twin-disk wear tests carried out with niobium microalloyed railway wheels with pearlitic and bainitic microstructures, bainite proved to be more

*e-mail: domingosminicucci@terra.com.br resistant than pearlite, because it can absorb plastic deformation better than pearlite ${ }^{6}$. The carbon range used in steels for railway wheels is $0.5 \% \mathrm{C}$ to $0.7 \% \mathrm{C}$, and the microalloying element most used in microalloyed railway wheels is vanadium associated with molybdenum. Recent investigations show that the association of niobium $(\mathrm{Nb})$ with molybdenum is more efficient in terms of improving mechanical properties and microstructure ${ }^{6 ; 7}$. Niobium reduces the austenite recrystallization temperature, pinning its grain boundaries with carbonitrides. Such effect limits the growth of grains by reducing the grain size with increasing strength and toughness ${ }^{8 ; 9}$. The solubilization of niobium in austenite depends on the temperature and the $\mathrm{C}$ content. As for railway wheels, the ideal temperature for total solubilization is around $1.200{ }^{\circ} \mathrm{C}$, the temperature adopted when heating the blocks for forging and rolling ${ }^{10 ; 11}$.

The major problem in railroad wheels applied on heavy haul transportation is shelling. It is characterized by plastic deformation on wheel tread regarding high wheel-rail contact load, which overtakes the wheel steel yield strength with tread material detachment, as observed in Figure $1^{4}$.

The railway wheel manufacturing process comprises the following steps: 
- Ingot manufacturing.

- Ingot cutting into blocks.

- Block heating on rotary furnace.

- First hot forging on hydraulic press.

- Hot rolling mill.

- Second hot forging process.

- Heat treatment.

- Machining.

- Final inspection.

The wheel heat treatment process involves austenitization, water quenching on the rim and flange, followed by tempering for stress relief, as shown in Figure 2. The AAR specification does not stipulate the temperature range for wheel tempering, because, so far, the wheel microstructure is fully pearlitic.

The wheel is heat-treated on black condition, and it is fully machined after the heat treatment, including the tread. The tread surface with direct water contact on microalloyed steel has martensite and bainite, yet martensite will be removed on machining operation. Only the more internal rim portion with bainite and pearlite will remain on the finished wheel. In this research, the introduction of a mixed microstructure with pearlite and bainite on the finished wheels with microalloyed materials ( $\mathrm{Nb} 1$ and $\mathrm{Nb} 2$ ) makes it necessary to know the temper embrittlement temperature range. Pearlite is not sensitive to this phenomenon, but martensite and bainite are ${ }^{12}$. Hence, for selecting the optimum tempering temperature of steels with bainitic structures, it is theoretically and practically important to investigate the behavior and mechanism of toughening and embrittlement of bainite during tempering. The usual main reasons for the occurrence of Tempering Bainite Embrittlement (TBE) and Tempering Martensite Embrittlement (TME) are the precipitation of cementite formed by the decomposition of retained austenite film at boundaries of bainitic or martensitic ferrite laths ${ }^{13}$. In this case, the fracture is cleavage (transgranular). Another possibility is segregation of impurities, such as $\mathrm{P}, \mathrm{S}, \mathrm{Sb}, \mathrm{Sn}$, and $\mathrm{N}$, which precipitate on prior-austenite grain boundaries at certain temperature ranges during tempering ${ }^{14}$. Upon that, the fracture type is normally intergranular.

The main objective of this research is to determine the temperature range of TBE/TME for $\mathrm{Nb} 1$ and $\mathrm{Nb} 2$ steels so as to avoid these phenomena during the wheel tempering process. Railroad wheels involve safety, so if they fail or break in service, the consequences could mean life loss or huge material damage. Thus, this investigation is relevant for new material development in the railroad field, with bainite on finished wheel tread.

\section{Materials and Methods}

The chemical compositions of the steels used in this research are shown in Table 1.

After hot forging and rolling operation, the black wheels were cut on the rim area in several pieces to reproduce the heat treatment process in laboratory according to wheel production line. The standard heat treatment process on wheel production line consists of wheel austenitization at $860{ }^{\circ} \mathrm{C}$, then water quenching on the rim for 4 minutes, and tempering in most cases with $500{ }^{\circ} \mathrm{C}$, sometimes less. The flowchart in Figure 3 shows the research steps.

\subsection{Heat treatment process in laboratory}

The black wheel portions (Figure 4) were austenitized in a laboratory furnace at $860{ }^{\circ} \mathrm{C}$ with thermocouple control on wheel rim, followed by water quenching for 4 minutes in a water tank where 20 millimeters of the wheel rim were immersed into the water, as shown in Figures 5, 6A, and 6B.

In order to determine the TBE/TME range temperature, the wheel portions were tempered at different temperatures, as follows:

Nb1 and C steels - 200, 220, 240, 260, 280, 300, 320, $340,360,380,400,420,440,460,480,500,520^{\circ} \mathrm{C}$.

Nb2 - 280, 300, 320, 340, 360, 500, $550{ }^{\circ} \mathrm{C}$.

\subsection{TBE / TME curve}

The TBE and TME curves were determined by the Charpy tests taking different tempering temperatures into consideration. The impact energy on TBE/TME temperature ranges is reduced, according to the example for AISI 15B41 with boron, in this case for TME. The TBE and TME curves have the same shape, which represents the same phenomenon, as shown in Figure $7^{15}$.

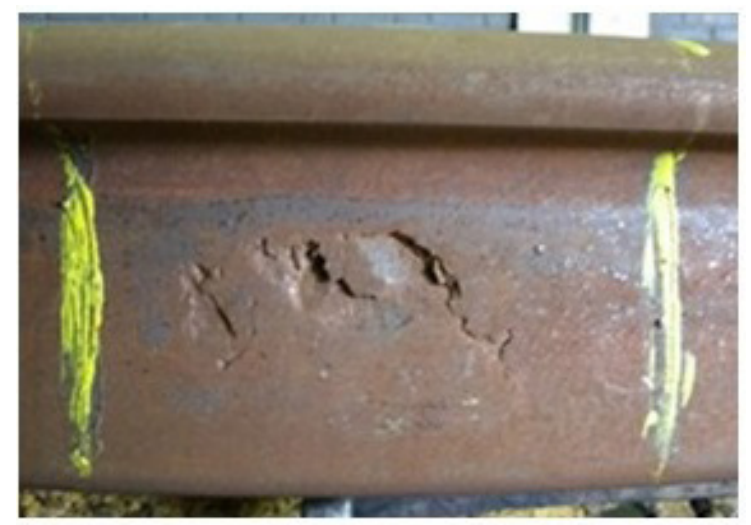

Figure 1. Wheel with shelling on the tread.

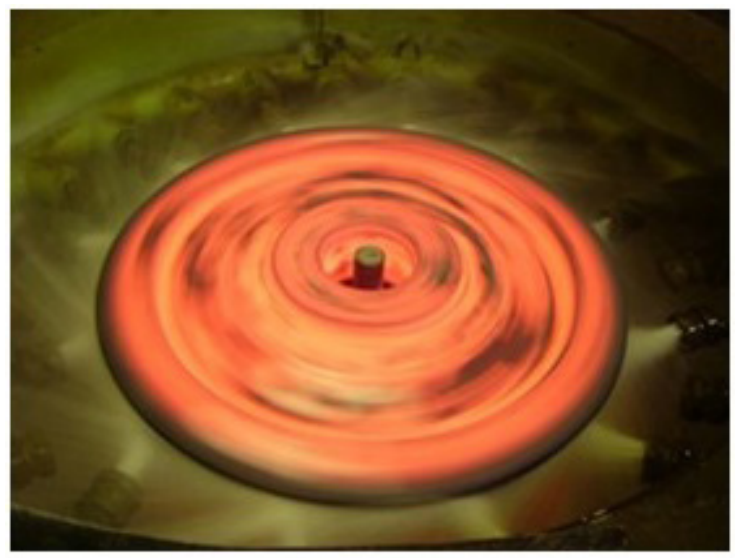

Figure 2. Railroad wheel heat treatment: water quenching on flange and tread on black condition. 
Table 1. Chemical compositions.

\begin{tabular}{ccccccccccc}
\hline Steel & $\mathrm{C}$ & $\mathrm{Mn}$ & $\mathrm{Si}$ & $\mathrm{S}$ & $\mathrm{P}$ & $\mathrm{Cr}$ & $\mathrm{Ni}$ & $\mathrm{Al}$ & $\mathrm{Nb}+\mathrm{Mo}$ \\
\hline Nb1 & 0.71 & 0.78 & $\mathbf{0 . 6 7 *}$ & 0.008 & 0.02 & 0.36 & 0.15 & 0.018 & $\mathbf{0 . 1 2 7 ^ { * }}$ \\
\hline Nb2 & 0.72 & 0.78 & $\mathbf{0 . 3 1}{ }^{*}$ & 0.008 & 0.02 & 0.38 & 0.18 & 0.014 & $\mathbf{0 . 2 3}^{*}$ \\
\hline $\mathbf{C}$ & 0.73 & 0.77 & 0.23 & 0.009 & 0.01 & 0.22 & 0.09 & 0.002 & 0.02 \\
\hline
\end{tabular}

*Alloy added

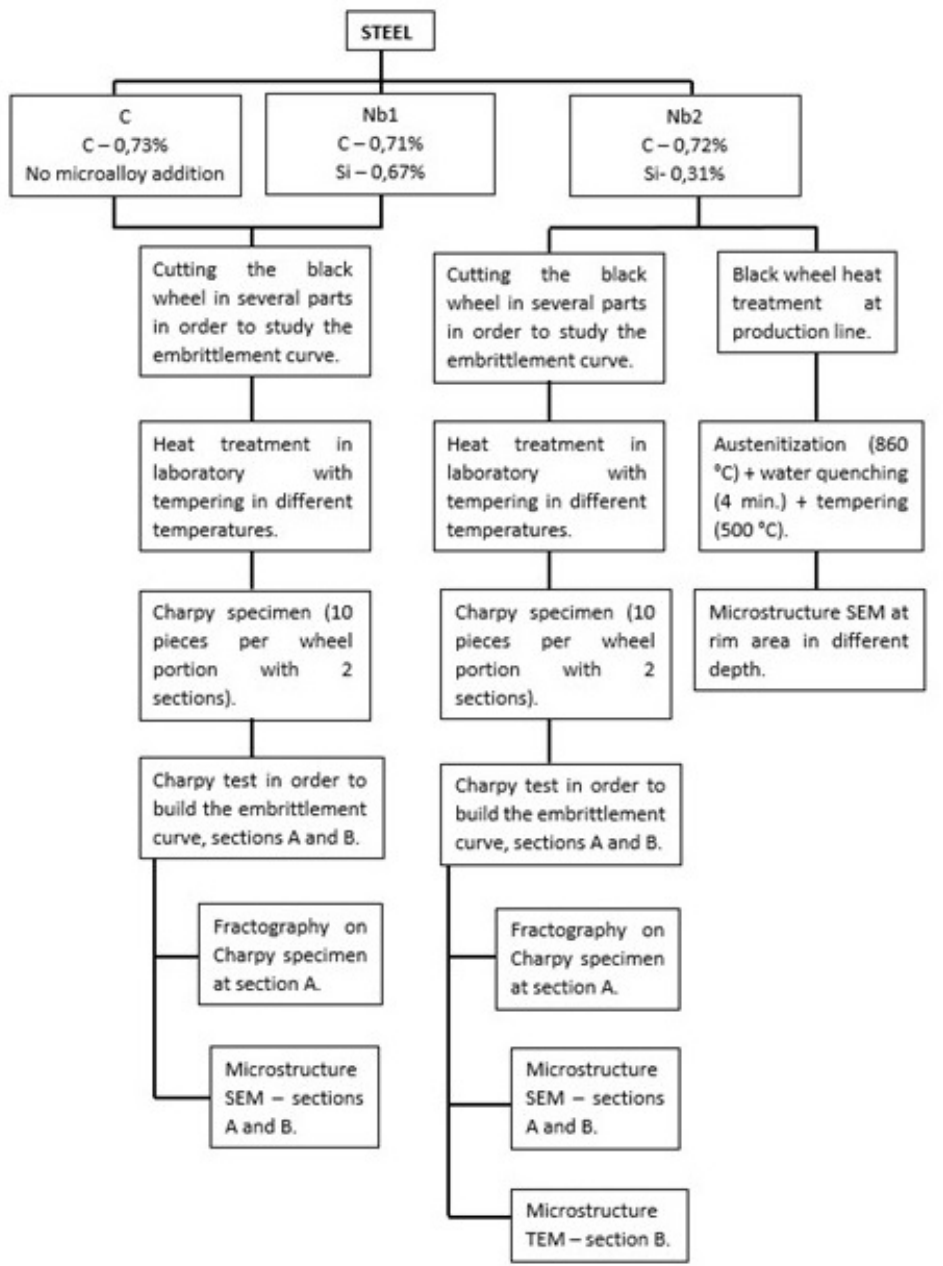

Figure 3. Research steps flowchart.

\subsection{Charpy specimens and tests}

The Charpy impact tests were performed with a U-Notch specimen, according to ASTM A 370-12. Figure 8 presents the specimen dimension and SEM region images on fracture section, and Figure 9 its position on the wheel rim. Forged railway wheels have a $5 \mathrm{~mm}$ radius over metal on the tread (average). In service, wheel wear reaches, on average, $20-25 \mathrm{~mm}$ in tread radius, until they achieve the end of their useful life (Figure 10). This is the reason why Charpy's specimens were extracted in two sections - to cover the entire useful area of the wheel track. After heat treatment, the black wheel portions were identified with 10 Charpy specimens per portion (Figure 11), separated into two sections and five positions, as follows:
Section A: close to tread surface with predominant martensitic and bainitic microstructure, which are partially removed during final wheel machining operation. In this section it is not possible to isolate the effect of martensite and bainite on the temper embrittlement phenomenon on the embrittlement curve; therefore, the graphics on this section were identified as TME/TBE.

Section B: this section is more valuable for this research, as it remains on the finished wheel rim, with a pearlitic and bainitic microstructure that corresponds to useful wheel tread area.

Each wheel portion was tempered at a different temperature. Each TME/TBE curve point represents the average result of all specimens at a specific temperature ( 5 points for section A and 5 points for section B). 


\subsection{Fractography and micrography}

The fractography and micrographs were performed with scanning electron microscope (SEM) Zeiss, model EVO MA 15. For micrographs, the samples were cut, sanded with sandpaper 320 - 1500 mesh, polished with diamond paste and $2 \%$ Nital. Transmission electronic microscopy

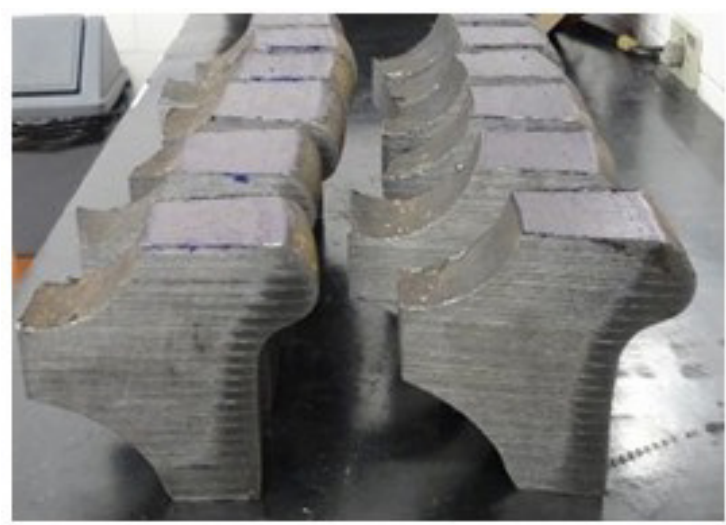

Figure 4. Wheel portions for heat treatment simulation.

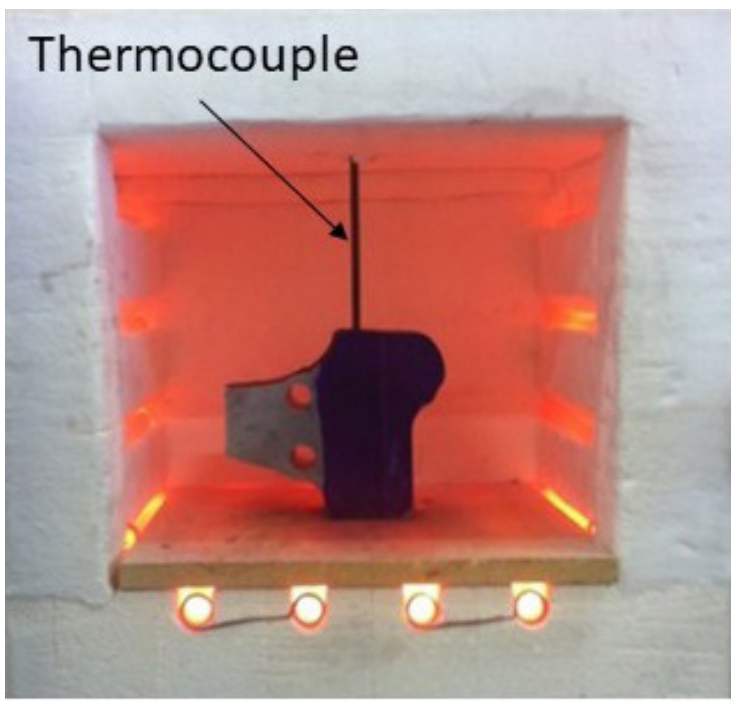

Figure 5. Laboratory furnace for austenitization with thermocouple on wheel rim.
(TEM) was applied to better evaluate the microstructure and to define the region of martensite and bainite. The transmission microscope used was FEI, model TECNAI $\mathrm{G}^{2}$ F20 HRTEM. The samples were treated and polished in the following sequence:

- $75 \%$ ethanol $+25 \%$ perchloric acid solution.

- Wash: ethanol + ethanol + acetone.

- Electrolytic polishing.

- $\quad$ Plasma cleaning for three minutes before microscopy analysis.

Fractography was carried out only in section A, as this region had the lowest values of absorbed energy in the Charpy test. The analysis of microstructure in SEM was conducted in sections $\mathrm{A}$ and $\mathrm{B}$, for investigating the homogeneity of the simulated heat treatment in the laboratory. The analysis of the microstructure in TEM was made only in section B of $\mathrm{Nb} 2$ steel in order to better define the microstructure at greater depths. In this analysis, samples from region 1, 4 and 5 (Figure 11) were verified, the last two from the wheel flange region so as to check the uniformity of the microstructure with respect to region 1, where the cooling condition is different.

A black wheel of $\mathrm{Nb} 2$ material was heat-treated in the production line, and its microstructure was checked to compare and validate the laboratory heat treatment process regarding the similarity of the microstructures.

\section{Results and Discussion}

The Charpy position and section indicated on following items are shown in Figure 11.

\subsection{Steel class $C$}

Steel class $\mathrm{C}$ has a predominant pearlitic microstructure, which is not sensitive to TBE/ TME, as seen in Figure 12. The embrittlement curve is in Figure 13A (section A) and 13B (section B). The average Charpy impact test result increases continuously with tempering temperature (section A), which indicates the presence of martensite and/or bainite (not detected on microstructure analyses). Section B remains stable, without any embrittlement indication, which indicates only pearlite on the microstructure. The fractography of the


Figure 6. (A) Water tank to reproduce the quenching operation in wheel production line; (B) Quenched part of the rim (20 mm). 
specimens show dimples and cleavage as fracture mechanism, as observed in Figure 14.

The fracture mechanisms are compatible with the pearlitic microstructure not sensitive to TBE/TME. The dimples

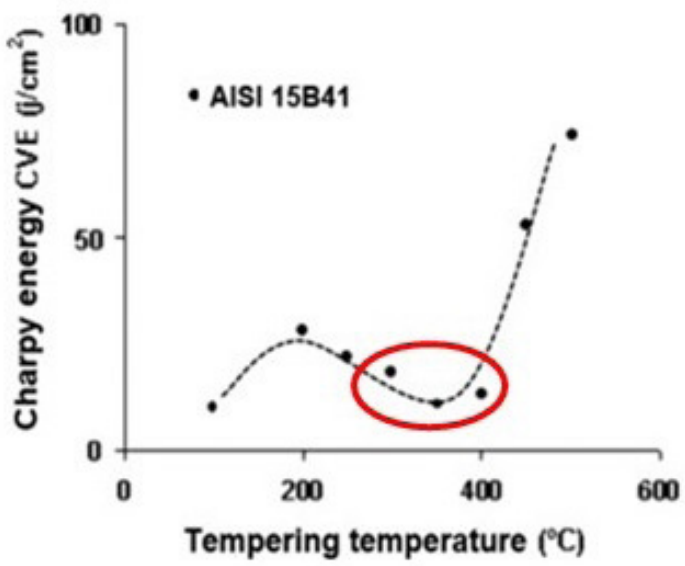

Figure 7. Temper embrittlement curve with impact energy reduction of TME range .
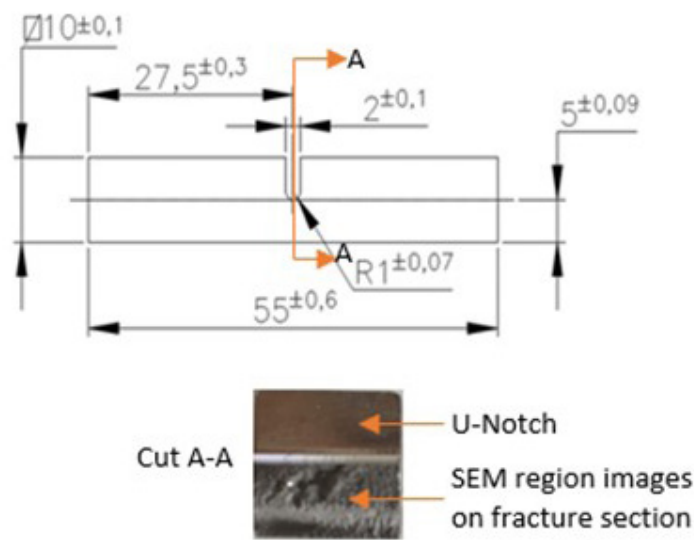

Figure 8. Charpy specimen dimensions in millimeters and SEM region images.

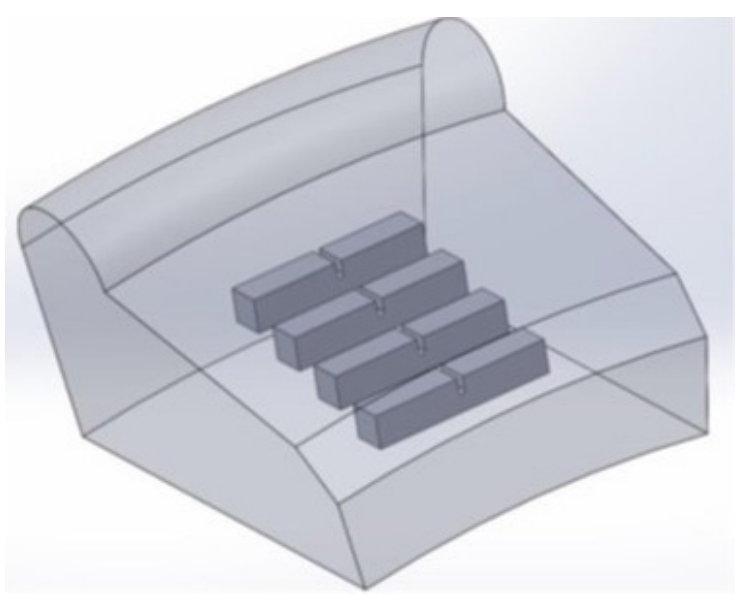

Figure 9. Charpy specimen position on the wheel rim. mechanism is characteristic of ductile fracture, having high plastic deformation during crack propagation with high energy absorption. Hence, the specimens with such feature have high Charpy results $(18 \mathrm{~J})$. On the other hand, as the cleavage is characteristic of fragile fracture, with low deformation and energy absorption with fast crack propagation, the Charpy results have low value $(6 \mathrm{~J})^{16}$.

\section{2. $\mathrm{Nb1}$ steel}

$\mathrm{Nb} 1$ steel has a mixed microstructure with martensite and bainite on section $\mathrm{A}$ and pearlite with bainite in section $\mathrm{B}$, both sensitive to TBE/TME, as shown in Figure 15. The embrittlement curves are in Figures 16A and 16B. The Charpy average test results reveal an embrittlement indication on sections $\mathrm{A}$ and $\mathrm{B}$. The fractography has dimples and cleavage as fracture mechanism, as observed in Figure 17.

Figures 16A and 16B show that the embrittlement temperature range for both sections is $280-380{ }^{\circ} \mathrm{C}$. The minimum Charpy test result is $6 \mathrm{~J}$ on the specimen tempered at $320{ }^{\circ} \mathrm{C}$ on section $\mathrm{A}$ at position 1 (trad area), and $8 \mathrm{~J}$ at the

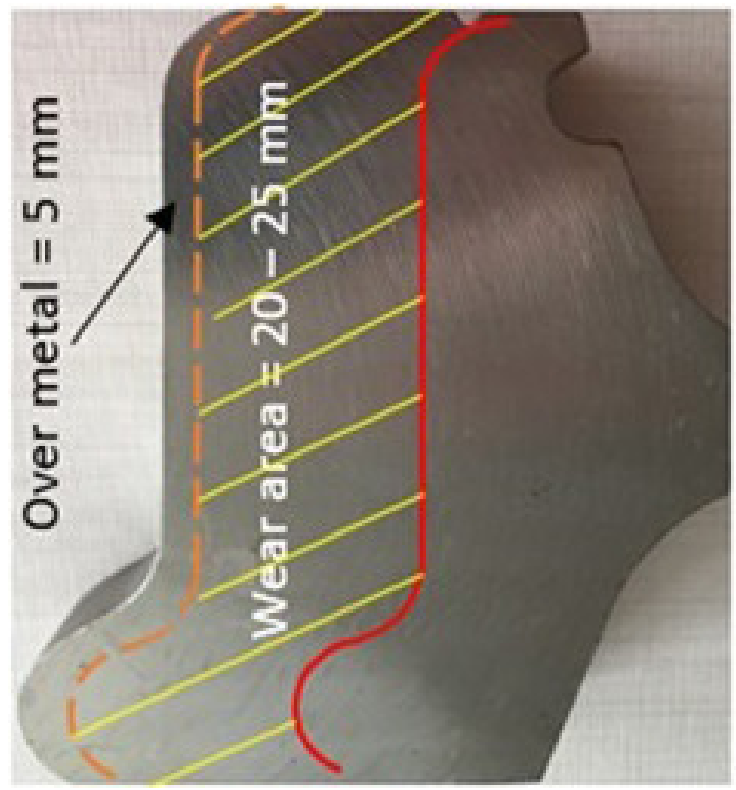

Figure 10. Forged wheel over metal and wear area dimension.

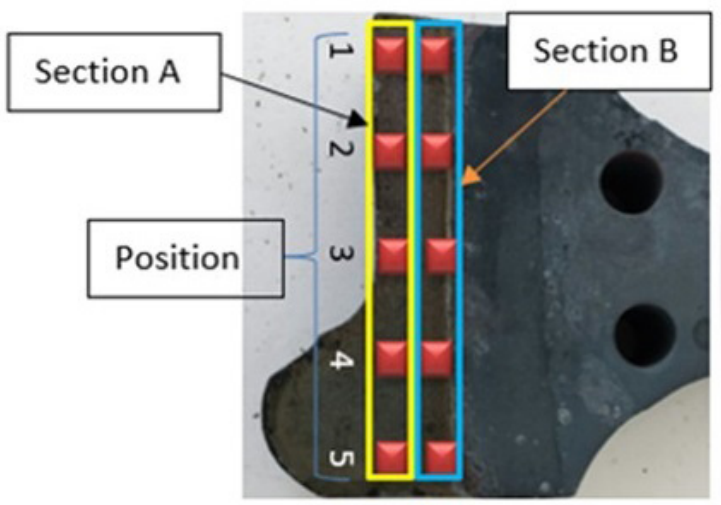

Figure 11. Location of the Charpy specimens on the wheel rim. 
same tempering temperature for section B at position 4 (wheel flange area). This result is compatible with the microstructures in Figure 15, which shows martensite with bainite on section $\mathrm{A}$, and bainite with pearlite on section $\mathrm{B}$. There are different fracture mechanisms inside and outside the embrittlement area. Section A, inside the embrittlement area, presents cleavage as its main fracture mechanism on the specimen, at position 1(tread area), tempered at $320^{\circ} \mathrm{C}(6 \mathrm{~J})$, with the lowest and more critical Charpy results in terms of embrittlement. Cleavage is characteristic of fragile and transgranular fracture, compatible with the specimen inside the embrittlement area. Section A, outside the embrittlement area, fractography presents only dimples as fracture mechanism on the specimen, at position 3 (tread area), tempered at $520^{\circ} \mathrm{C}(16 \mathrm{~J})$, with higher Charpy
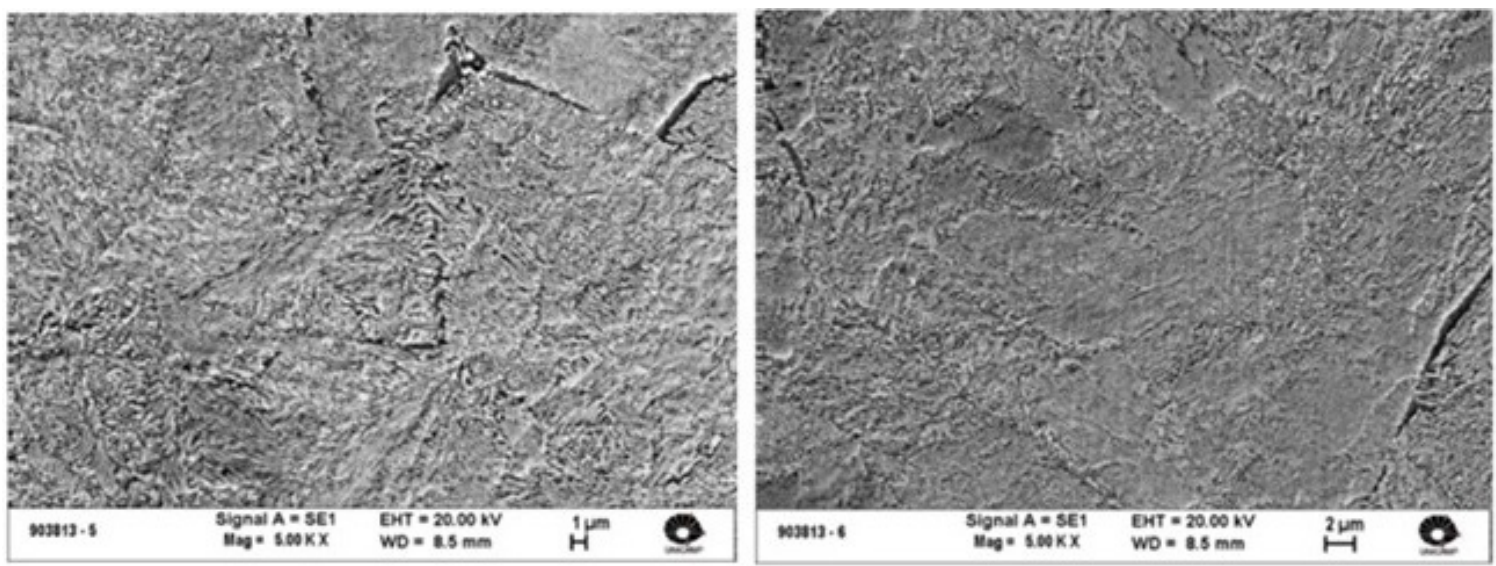

Figure 12. Class C steel: Pearlitic microstructures on Charpy specimens section A, $2 \%$ Nital per $10 \mathrm{~s}$ (left). Section B (right). No evidence of martensite or bainite in section A and B (SEM image).
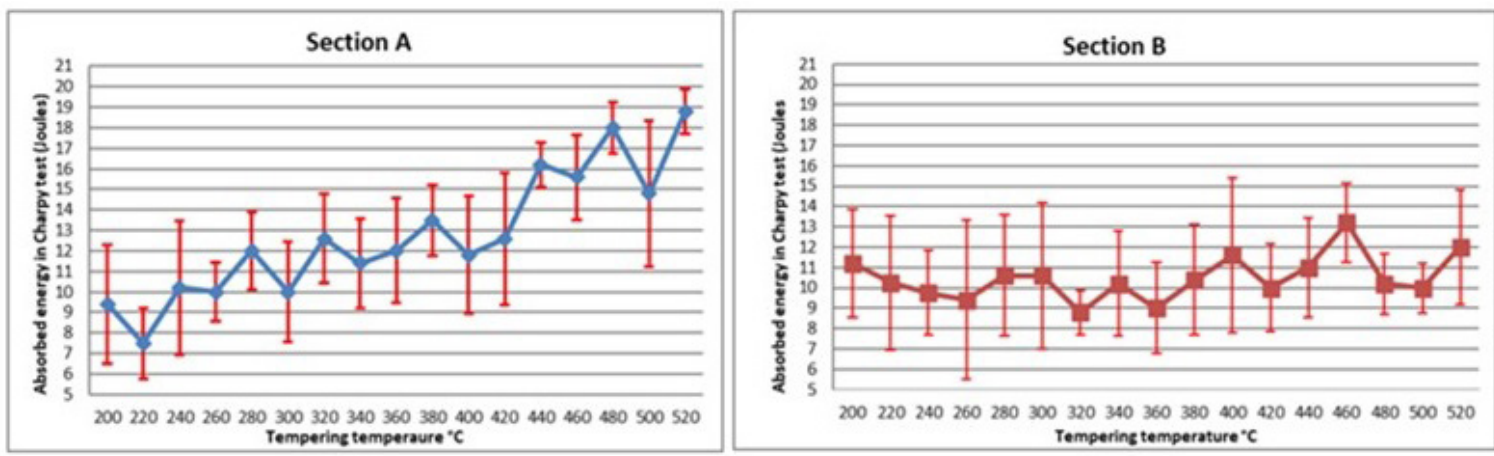

Figure 13. Section A: curve for class $C$ steel; Section B: curve for class $C$ steel.
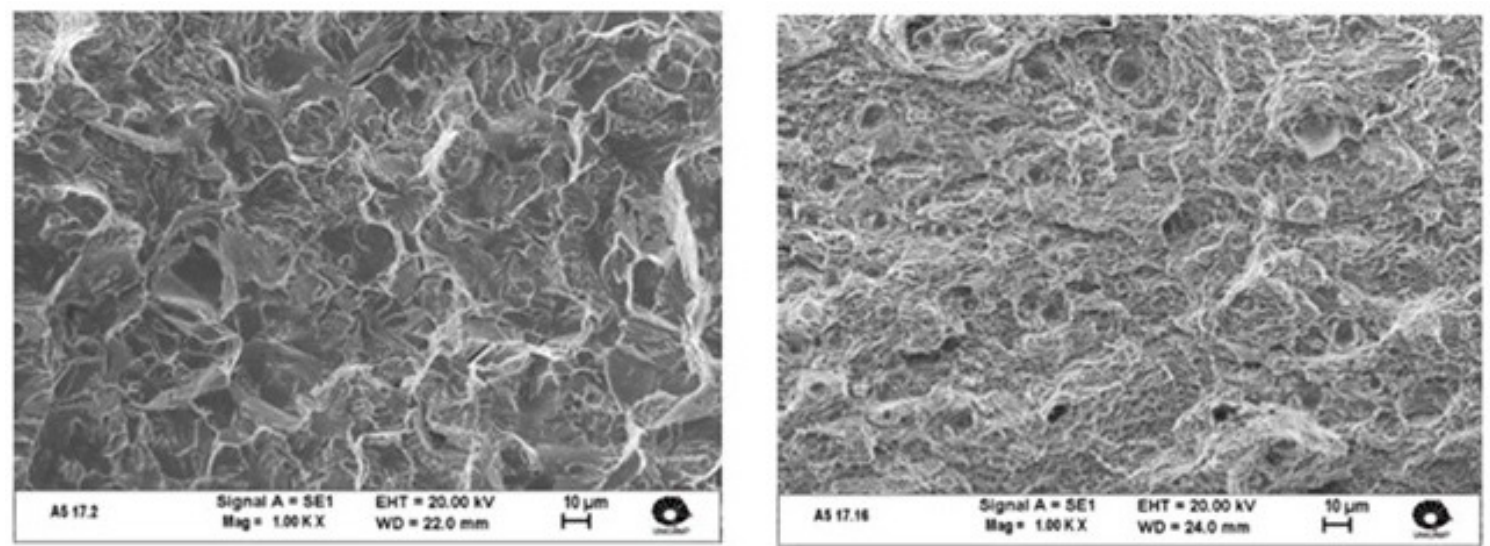

Figure 14. Class C steel: Fractography section A and position 5, tempered at $220^{\circ} \mathrm{C}$ (6 Joules) with cleavage and areas with few dimples (left). Fractography section A and position 5, tempered at $500^{\circ} \mathrm{C}$ (18 Joules) with dimples (right). 
results. Dimples are characteristic of ductile fracture with high energy absorption, which is compatible with the graphics in Figures 16A and 16B. According to Horn ${ }^{17}$, TME is embrittlement from cementite precipitation during tempering. In high strength steels, this occurs at grain lath boundaries, aided by the thermal decomposition of interlath films of retained austenite. In steels, where the level of impurities and retained austenite is low, the dominant embrittlement mechanism is the tensile fracture of such carbides, and the resulting fracture mechanism will be transgranular cleavage.

However, in steels containing sufficient residual impurity content, or microstructures particularly susceptible to grain
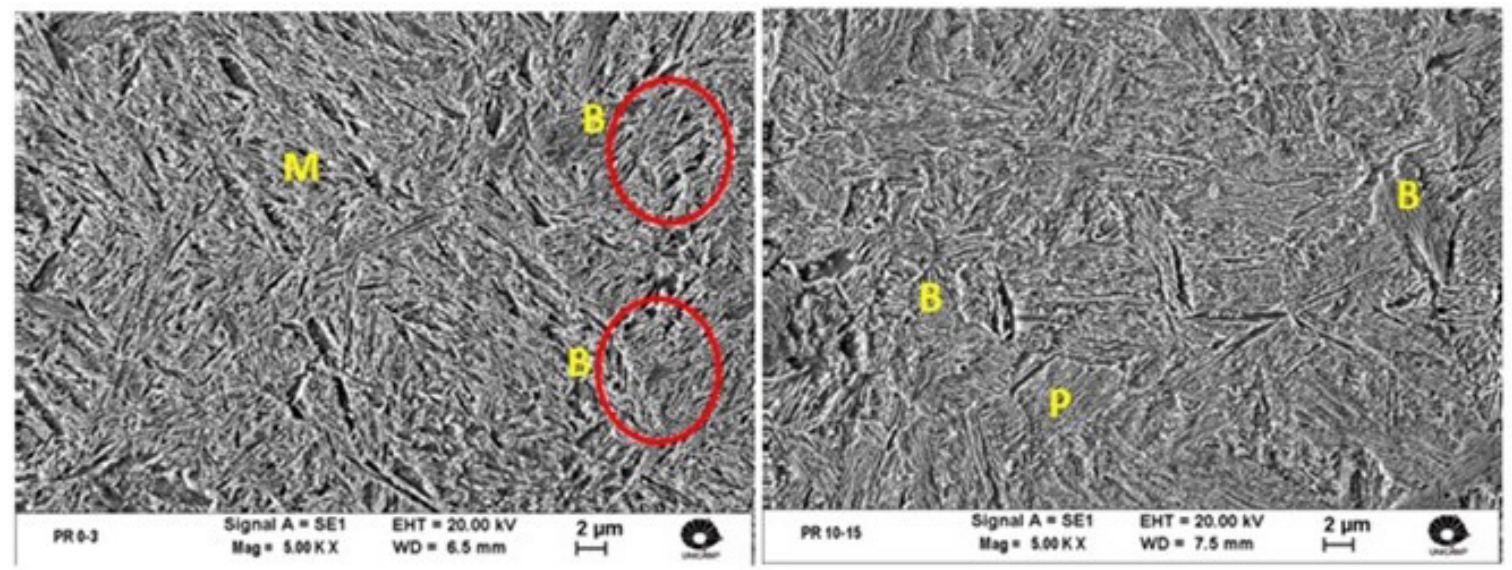

Figure 15. $\mathrm{Nb} 1$ steel: Martensitic and bainitic microstructure on section $\mathrm{A}$, with $2 \% \mathrm{Nital}$ per $10 \mathrm{~s}$ (left). Pearlitic and bainitic microstructure on section B with $2 \%$ Nital per $10 \mathrm{~s}$ (right). $\mathrm{M}=$ Martensite, $\mathrm{B}=$ Bainite, and $\mathrm{P}=$ Pearlite. The red circles show the bainite microstructure islands (SEM images).
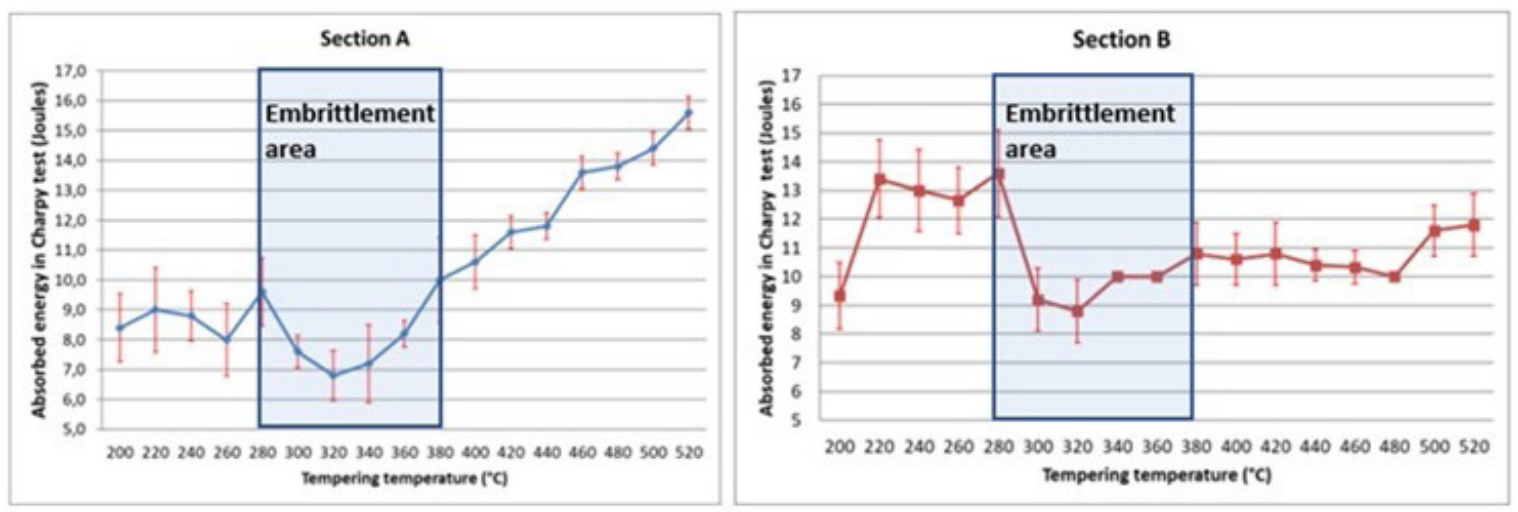

Figure 16. Section A: TBE/TME curve Nb1 material; Section B: TBE/TME curve Nb1 material.
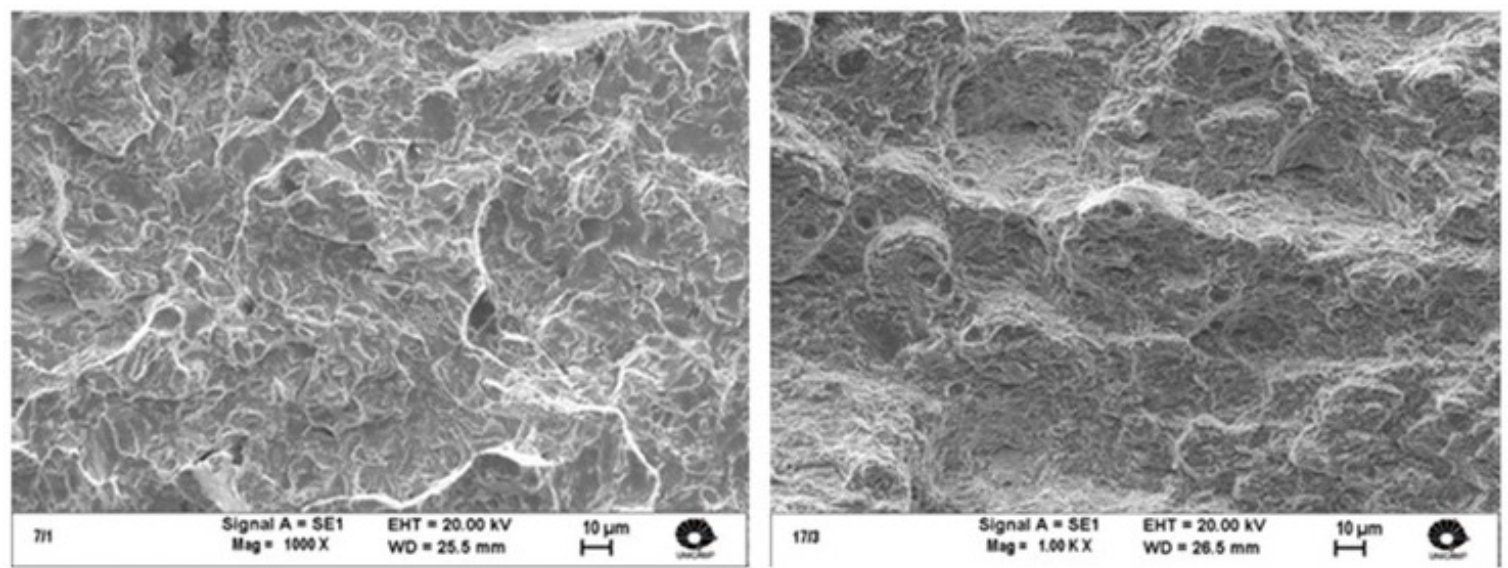

Figure 17. Nb1 steel: Fractography section A and position 1, tempered at $320^{\circ} \mathrm{C}$ (6 Joules) with cleavage (left). Fractography section $\mathrm{A}$ position 3 , tempered at $520^{\circ} \mathrm{C}$ (16 Joules) with dimples (right) (SEM image). 
boundary embrittlement, these impurities, such as $\mathrm{P}$ or $\mathrm{S}$, are prone to segregate to prior grain boundaries during austenitization. In the embrittlement range, the combination of cementite precipitates and impurities in prior-austenite grain boundaries will lead to the lowest cohesion at grain boundary carbide/matrix interface, resulting in intergranular fracture, as observed in Figure $18^{17}$.

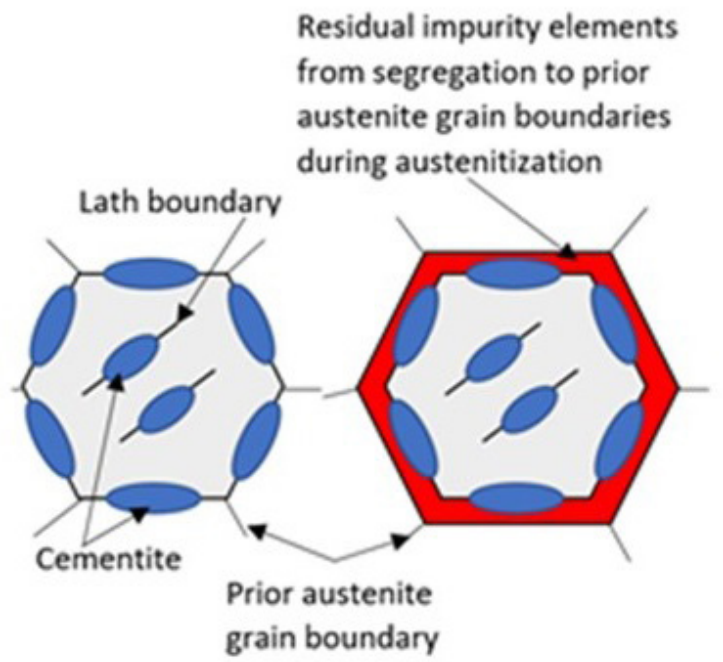

Figure 18. Transgranular cleavage fracture (left). Intergranular fracture (right) $)^{17}$.
$\mathrm{Nb} 1$ steel has a silicon $(\mathrm{Si})$ addition twice as much as $\mathrm{Nb} 2$ steel does (Table 1), which changes some characteristics of the embrittlement phenomenon ${ }^{17}$. During tempering, there is $\mathcal{E}$-carbide precipitation, and TME occurs when this carbide transforms into cementite. Embrittlement happens because of the replacement of $\mathcal{E}$-carbide with interlath cementite during tempering, and the mechanical instability of interlath films of austenite is a consequence of this carbide precipitation. The Si addition enhances the stability of $\mathcal{E}$-carbide; for this reason, it retards the formation and growth of cementite, thus increasing the thermal and mechanical stability of retained austenite at higher tempering temperatures ${ }^{17}$.

\subsection{Nb2 steel}

$\mathrm{Nb} 2$ steel also has a mixed microstructure with martensite, pearlite and bainite in section $\mathrm{A}$, and another one with pearlite and bainite in section $\mathrm{B}$, both sensitive to TBE/TME, as observed in Figure 19. The embrittlement curves are in Figures 20A and 20B. The average Charpy test results reveal an embrittlement area on sections A and B. The fractography has dimples and cleavage as fracture mechanism, as shown in Figure 21 for section A. For Nb2 steel, section B microstructure was also characterized in TEM for checking it in detail, Figures 22 and 23. The behavior of $\mathrm{Nb} 2$ steel was similar to that of $\mathrm{Nb} 1$, and the embrittlement range was between $280-360^{\circ} \mathrm{C}$. The lowest impact test result on section A was $7 \mathrm{~J}$ at $300^{\circ} \mathrm{C}$, position 3 (tread area), less than $320^{\circ} \mathrm{C}$ observed for $\mathrm{Nb} 1$ steel. The
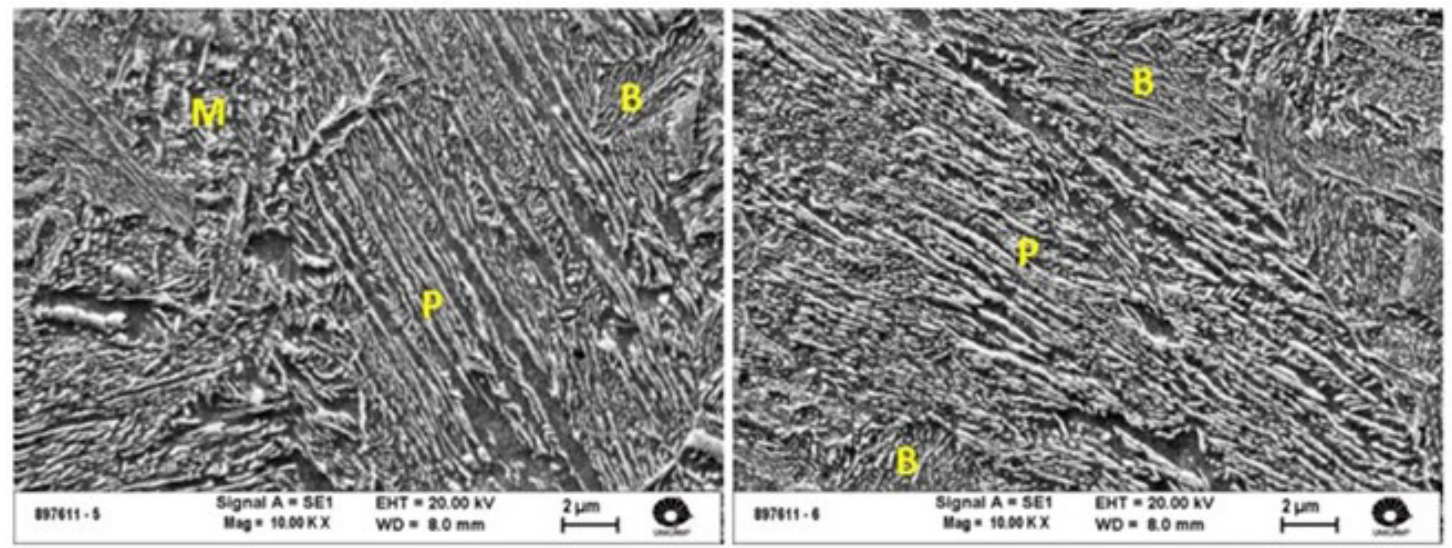

Figure 19. Nb2 steel: Martensitic, bainitic and pearlitic microstructure on section A with $2 \%$ Nital per $10 \mathrm{~s}$ (left). Pearlitic and bainitic microstructure on section $\mathrm{B}$ with $2 \%$ Nital per $10 \mathrm{~s}$ (right). $\mathrm{M}=$ Martensite, $\mathrm{B}=$ Bainite, and $\mathrm{P}=$ Pearlite (SEM image).
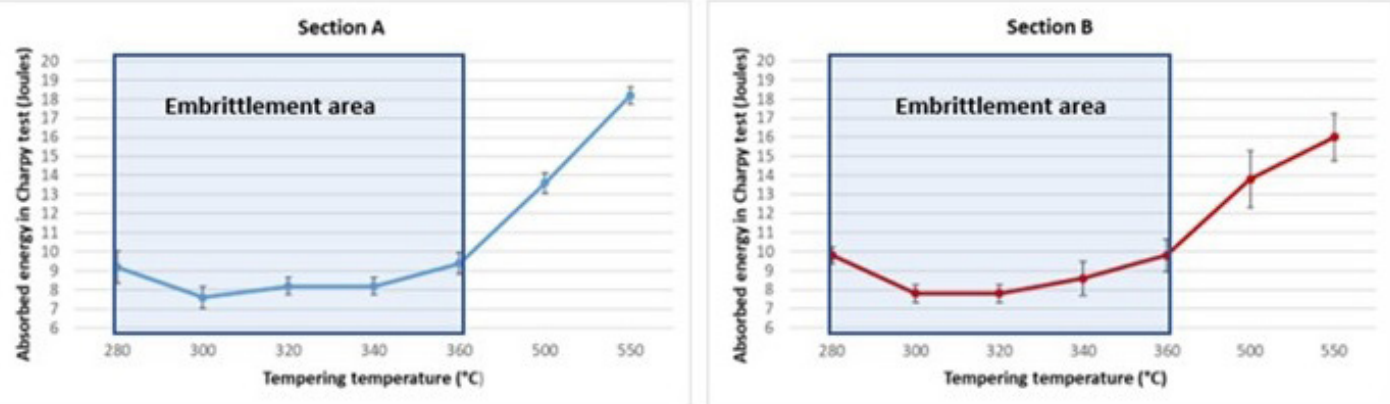

Figure 20. Section A: TBE/TME curve Nb2 steel; Section B: TBE/TME curve Nb2 steel. 



Figure 21. Nb2 steel: Fractography section A and position 3, tempered at $300{ }^{\circ} \mathrm{C}$ (7 Joules) with cleavage (left). Fractography section $\mathrm{A}$ and position 1 , tempered at $500{ }^{\circ} \mathrm{C}$ (14 Joules) with dimples (right) (SEM image).
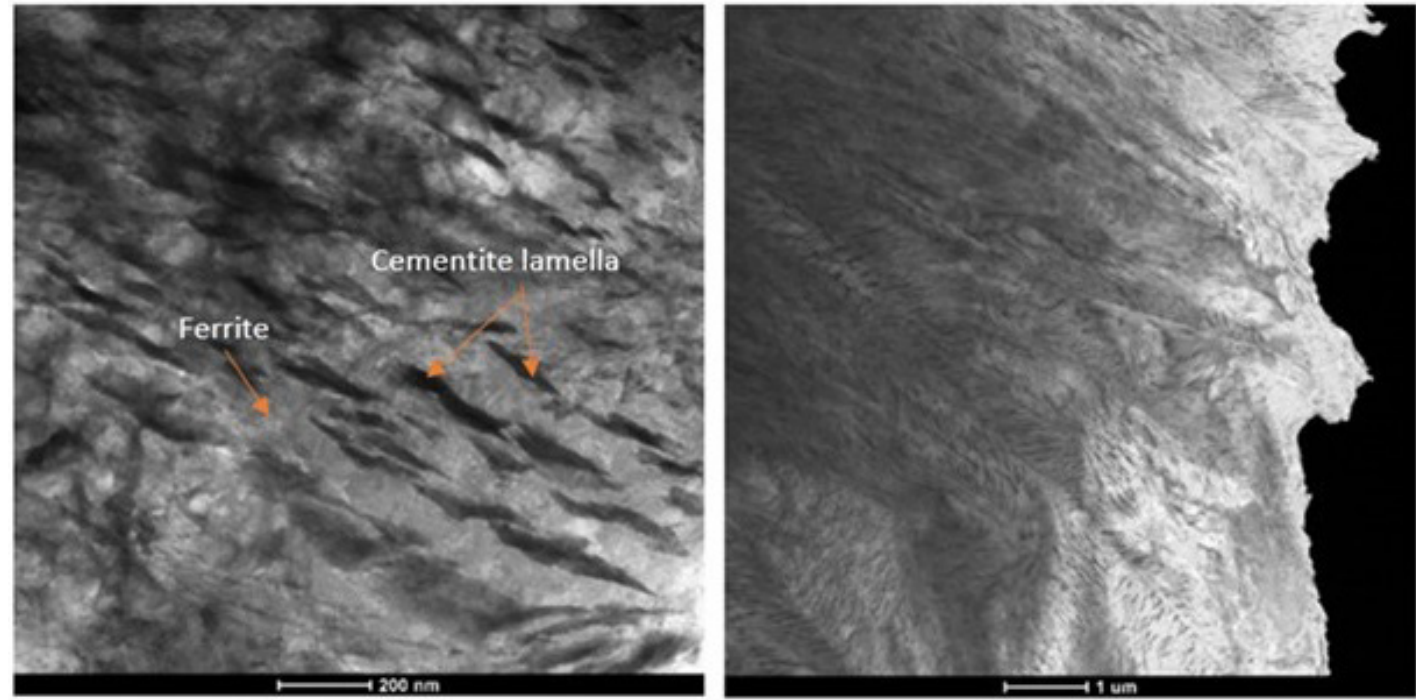

Figure 22. $\mathrm{Nb} 2$ steel: TEM images of Charpy specimens in section $\mathrm{B}$ and position 4 (wheel flange area), tempered at $300^{\circ} \mathrm{C}(7 \mathrm{~J})$. Minimum Charpy result inside the embrittlement area. Microstructure is fully bainite (B).
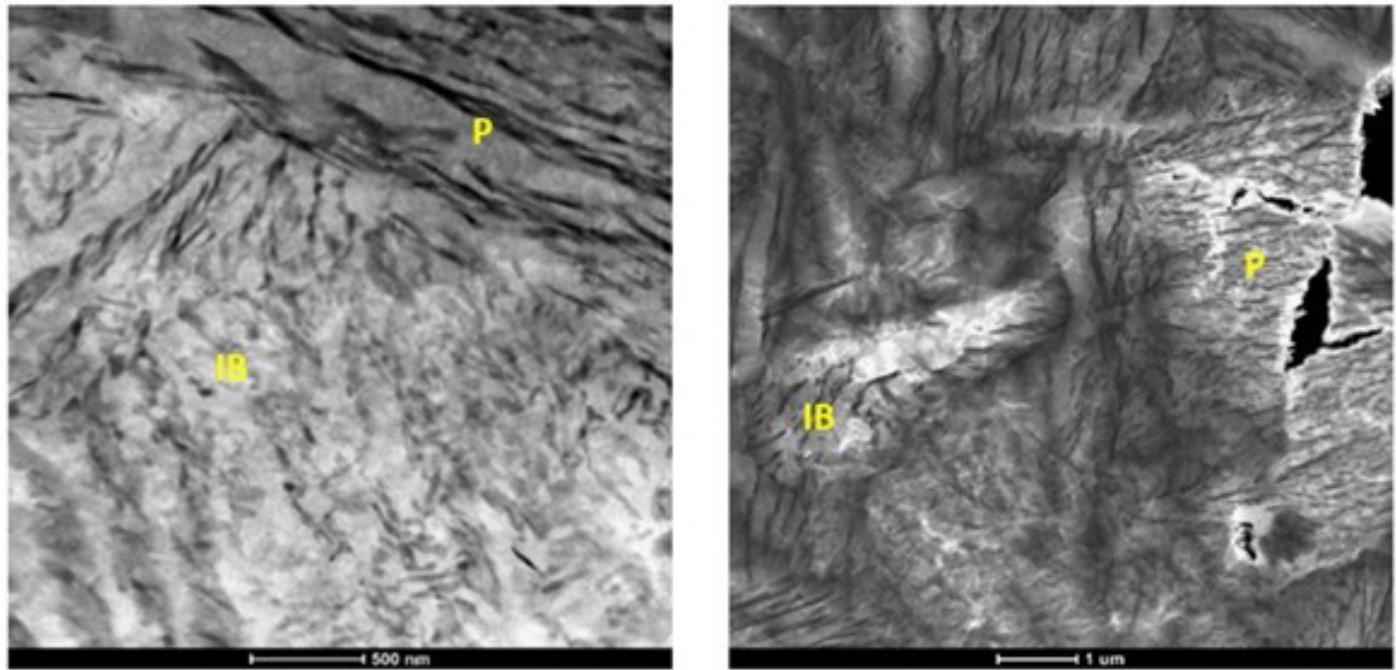

Figure 23. Nb2 steel: TEM images of Charpy specimens in section B and position 1 (out of flange area), tempered at $500{ }^{\circ} \mathrm{C}(14 \mathrm{~J})$ ) Maximum Charpy result out of embrittlement area. Microstructure is inferior bainite (IB) and pearlite (P). 


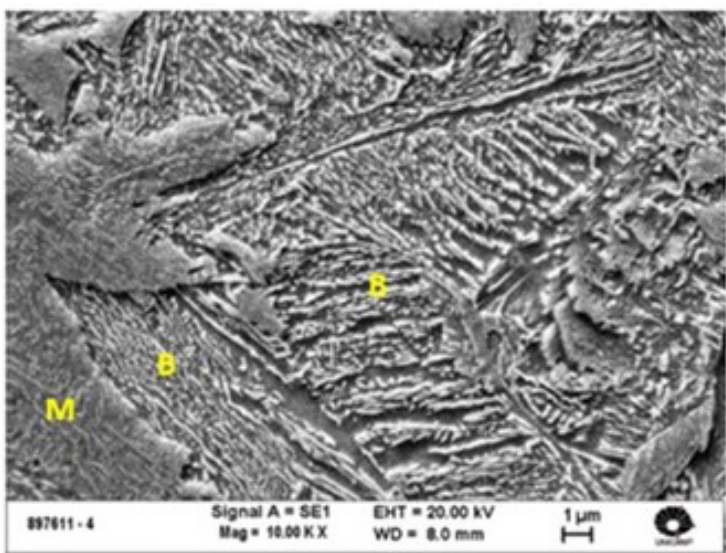

Figure 24. $\mathrm{Nb2}$ steel: Black wheel $5 \mathrm{~mm}$ deep with martensite and bainite. $\mathrm{B}=$ bainite and $\mathrm{M}=$ martensite (SEM image).

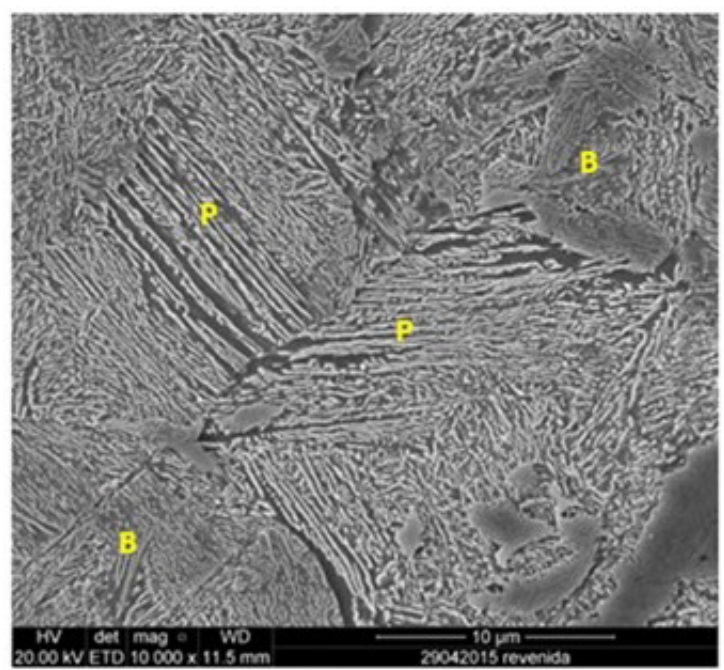

Figure 25. Nb2 steel: Black wheel $15 \mathrm{~mm}$ deep with pearlite and bainite. $\mathrm{B}=$ bainite and $\mathrm{P}=$ pearlite (SEM image).

difference of $20^{\circ} \mathrm{C}$ refers to the $\mathrm{Si}$ content addition to the $\mathrm{Nb} 1$ material, which delays the embrittlement phenomenon by stabilizing $\mathcal{E}$-carbide.

The $\mathrm{S}$ segregation at prior-austenite grain boundary could be responsible for the embrittlement process. According to Ebrahim $^{18}, 0.02 \% \mathrm{~S}$ is enough for leading to the embrittlement process, which was the same $\mathrm{S}$ concentration in $\mathrm{Nb} 1$ and $\mathrm{Nb} 2$ steels. However, the TEM analyses did not detect this kind of segregation.

The TEM analyses showed only bainitic microstructure on the specimen tempered at $300^{\circ} \mathrm{C}$ inside the embrittlement area. For the specimen tempered at $500{ }^{\circ} \mathrm{C}$ - the typical tempering temperature in railroad wheel manufacturing process - the microstructure was pearlitic and bainitic. Pearlite has more toughness than bainite, which could help increase the toughness and Charpy test results, as well as avoid embrittlement.

The fractography analyses shows the same behavior of $\mathrm{Nb} 1$ steel, that is, cleavage inside the embrittlement area and dimples out of it.

\subsection{Black wheel}

The black wheel heat treated on manufacturing line, with the same process used on laboratory simulation, presented a similar microstructure in comparison with the Charpy specimen heat treated in laboratory. The following microstructures $5 \mathrm{~mm}$ deep from wheel tread (middle of section $\mathrm{A}$ ) and $15 \mathrm{~mm}$ deep (middle of section $\mathrm{B}$ ), are on Figures 24 and 25.

\section{Conclusions}

The results of this research indicate the following:

- The tempered embrittlement temperature range, detected by the Charpy tests, for $\mathrm{Nb} 1$ material is $280^{\circ}-380^{\circ} \mathrm{C}$ and for $\mathrm{Nb} 2$ material $280^{\circ}-360^{\circ} \mathrm{C}$. This temperature range must be avoided during railroad wheel tempering process for microalloyed steel with bainite in its microstructure. Railroad wheels involve safety, so any failure in service must be prevented and avoided.

- The microstructure detected on black wheel, heat treated at manufacturing line, is similar to the one on the Charpy test specimen, both tempered with $500{ }^{\circ} \mathrm{C}$ (Figure 23). This validates the heat treatment process carried out in the laboratory, which reproduced the same conditions found in the wheel manufacturing line.

- Charpy specimens were extracted for fractography from several positions of the wheel tread, outside and in the flange area. There was no difference in the fracture mechanism regarding the position of the specimen since the cooling of the wheel portions is identical in all parts when immersed in the tank. This finding eliminates variations in the embrittlement curve with respect to the position of the specimen.

- Pearlite is not sensitive to the embrittlement phenomenon, which is confirmed by this study (class C steel, in section B). As embrittlement poses no concern to the railroad wheels with only pearlite on their microstructure (Class C), the AAR does not specify the tempering temperature range.

- The Si addition level to $\mathrm{Nb} 1$ steel, twice as much as that to $\mathrm{Nb} 2$ steel, stabilized the $\mathcal{E}$-carbide and delayed the cementite formation. Thus, the lowest Charpy test result inside embrittlement area occurred at $320^{\circ} \mathrm{C}$. In Nb2 material, with $50 \%$ less Si addition, this result happened at $300{ }^{\circ} \mathrm{C}$.

- All fractography inside the embrittlement area showed a cleavage as the main feature of transgranular fractures in the Charpy specimens. The main cause of embrittlement process on $\mathrm{Nb} 1$ and $\mathrm{Nb} 2$ steels was cementite precipitation on bainite or martensite lath and grain boundaries.

- Embrittlement may be associated with segregation of impurities (P and $\mathrm{S})$ at prior grain boundaries during austenitization. In this case, the fractures analyzed by fractography must be intergranular, through grain boundary. Because all fractures in this research were transgranular and no $\mathrm{S}$ or $\mathrm{P}$ 
segregation was detected on SEM and TEM, this possibility is rejected in such an instance.

- $\quad$ Reasons for the occurrence of TBE/TME may be as follows:

- The mechanisms of brittle fracture involve the cracking of interlath cementite platelets formed by the decomposition of retained austenite and the subsequent propagation of cleavage cracks across the laths of common orientation in martensite and bainite packet.

- Precipitation of cementite formed by decomposition of retained austenite film at boundaries of bainitic ferrite laths or around the martensite and austenite islands during soaking at the tempering temperature.

- The $\varepsilon$-carbide precipitation during tempering, when this carbide transforms into cementite. The TME/TBE happens because of the replacement of $\mathcal{E}$-carbide with interlath cementite during tempering, and the mechanical instability of interlath films of austenite is a consequence of this carbide precipitation.

\section{Acknowledgements}

This research was performed with the collaboration of MWL Brasil Rodas \& Eixos and the Mechanical Engineering, Manufacturing and Materials Department of Campinas University (UNICAMP, Campinas - Brazil).

\section{References}

1. Sharma S, Sangal S, Mondal K. Wear behavior of bainitic rail and wheel steels. Mater Sci Technol. 2016;32(4):266-74.

2. Zapata D, Jaramillo J, Toro A. Rolling contact and adhesive wear of bainitic and pearlitic steels in low load regime. Wear Magazine. 2011;271:393-9.

3. Hemsworth A, Orjekh I. Development of 42 tons axle load heavy haul wheel. In: International Heavy Haul Congress; 2015 June 21-24; Perth. Proceedings. Virginia: IHHA; 2015. p. 617-626.

4. Stone DH, Moyar GJ, Guins TS. An interpretative review of wheel shelling and spalling. ASME Rail Transportation. 1992;5:97-103.
5. Narayanaswamy B, Hodgson P, Beladi H. Comparisons of the two-body abrasive wear behavior or four different ferrous microstructures with similar hardness levels. WEAR. 2016;350351:155-65.

6. Resende AB, Fonseca ST, Fernandes FM, Miranda RS, Grijalba FAF, Farina PFS. et al. Wear behavior of bainitic and pearlitic microstructures from microalloyed railway wheels. Wear. 2020;456:456-7.

7. Minicucci DJ, Fonseca ST, Villas Boas RL, Goldenstein H, Mei PR. Development of niobium microalloy steel for railway wheel with pearlitic and bainitic microstructure. Mater Res. 2020;22(6)

8. Anijdan Mousavi SH, Yue S. The necessity of dynamic precipitation for the occurrence of no-recrystallization temperature in $\mathrm{Nb}$ microalloyed steel. Mater Sci Eng A. 2011;528:803-7.

9. Liu C, Huang Y, Liu H, Jiang M. Effects and mechanisms of niobium on the fracture toughness of heavy rail steel. Advanced Materials Research. 2011:163-167;110-116.

10. Anijdan Mousavi SH, Yue S. The effect of cooling rate and cool deformation through strain-induced transformation, on microstructural evolution and mechanical properties of microalloy steel. Metall Mater Trans. 2012:43A;1140-1162.

11. Anijdan Mousavi SH, Rezaeian A, Yue S. The effect of chemical composition and austenite conditioning on the transformation behavior of microalloyed steels. Mater Charact. 2012;63:27-38.

12. Viswanathan R, Joshi A. Effect of microstructure on the temper embrittlement of Cr-Mo-V steels. Metall Trans, A, Phys Metall Mater Sci. 1975;6:2289-97.

13. Hu GL, Liu ZT, Wang P, Hwa WJ, Kang MK. Mechanism of tempered bainite embrittlement in some structural steels. Mater Sci Eng. 1991;A141:221-7.

14. Marcomini JB, Goldenstein H. Nova liga de Fe-C-Mn-Si-Cr para rolamentos: curvas de revenimento e fragilização da martensita revenida. Tecnol Metal Mater Min. 2012;9(4):324-9.

15. Lescano DE, Silvetti SP. Study of microstructure and tempered martensite embrittlement in AISI 15B41 steel. Proc Mat Science. 2011;1:134-40.

16. Dieter EG. Mechanical metallurgy. 3rd ed. United States: McGraw-Hill; 1986. 740 p.

17. Horn RM, Ritchie RO. Mechanisms of tempered martensite embrittlement in low alloy steels. Metall Trans A. 1978;9A:103952.

18. Ebrahimi FZ, Krauss G. Mechanisms of tempered martensite embrittlement in medium-carbon steels. Acta Metall. 1984;32:176777. 